\title{
Mitochondrial dysfunction in lung ageing and disease
}

\author{
Suzanne M. Cloonan (10) ${ }^{1,2}$, Kihwan Kim ${ }^{1}$, Pauline Esteves ${ }^{3,4}$, Thomas $\operatorname{Trian}^{3,4}$ \\ and Peter J. Barnes ${ }^{5}$
}

Affiliations: 'Division of Pulmonary and Critical Care Medicine, Joan and Sanford I. Weill Dept of Medicine, New York, NY, USA. ${ }^{2}$ School of Medicine, Trinity College Dublin and Tallaght University Hospital, Dublin, Ireland. ${ }^{3}$ Univ-Bordeaux, Centre de Recherche Cardio-thoracique de Bordeaux, U1045, Dépt de Pharmacologie, CIC 1401, Bordeaux, France. ${ }^{4}$ INSERM, Centre de Recherche Cardio-thoracique de Bordeaux, U1045, CIC 1401, Bordeaux, France. ${ }^{5}$ National Heart and Lung Institute, Imperial College, London, UK.

Correspondence: Peter J. Barnes, National Heart and Lung Institute, Dovehouse St, London, SW3 6LY, UK. E-mail: p.j.barnesđimperial.ac.uk

@ERSpublications

We provide an up-to-date synopsis of the diverse nature of the mitochondrion in maintaining cellular homeostasis in an array of lung cell types and what happens when these pathways become dysfunctional with ageing and with acute or chronic lung disease. https://bit.ly/30jNKjZ

Cite this article as: Cloonan SM, Kim K, Esteves $\mathrm{P}$, et al. Mitochondrial dysfunction in lung ageing and disease. Eur Respir Rev 2020; 29: 200165 [https://doi.org/10.1183/16000617.0165-2020].

ABSTRACT Mitochondrial biology has seen a surge in popularity in the past 5 years, with the emergence of numerous new avenues of exciting mitochondria-related research including immunometabolism, mitochondrial transplantation and mitochondria-microbe biology. Since the early 1960s mitochondrial dysfunction has been observed in cells of the lung in individuals and in experimental models of chronic and acute respiratory diseases. However, it is only in the past decade with the emergence of more sophisticated tools and methodologies that we are beginning to understand how this enigmatic organelle regulates cellular homeostasis and contributes to disease processes in the lung. In this review, we highlight the diverse role of mitochondria in individual lung cell populations and what happens when these essential organelles become dysfunctional with ageing and in acute and chronic lung disease. Although much remains to be uncovered, we also discuss potential targeted therapeutics for mitochondrial dysfunction in the ageing and diseased lung. 


\section{Introduction}

Mitochondria are parasymbiotic organelles that contain their own DNA, metabolome, transcriptome and proteome, but rely on their host for replication, energy intermediates and proteins. Mitochondria supply energy and metabolites to the "host" cell by regulating the continuous aerobic oxidation of fatty acids, while at the same time consuming the end products of glucose, glutamine and amino acid degradation from the "host", generating energy (adenosine triphosphate; ATP) via the electron transport chain (ETC). Mitochondria form an interconnected intracellular network changing their shape, size and location inside the cell in response to a plethora of stimuli, including nutrient availability from the "host" $[1,2]$. Such movement relies on a series of membrane remodelling events involving cycles of fusion and division (fission) which also allows for the generation of new mitochondria (biogenesis) to supply the "host" cell with a constant reserve of healthy mitochondria; processes reliant on both nuclear-encoded and mitochondrial-encoded proteins [3]. When a healthy pool of mitochondria is threatened, such as loss or damage of the mitochondrial genome, defective mitochondria are removed by the "host" through selective encapsulation into autophagosomes, that are in turn delivered to the lysosome for degradation, a process termed mitophagy. Under conditions of intense stress, mitochondria also play a central role in extrinsic/ intrinsic apoptosis, necrosis/necroptosis and pyroptosis programmed cell death pathways $[4,5]$.

Mammalian mitochondrial DNA (mtDNA), which encodes merely 37 genes, is highly susceptible to oxidative DNA damage and acts as a damage-associated molecular pattern (DAMP) when found outside the mitochondrial compartment [6]. Cytosolic or extracellular oxidised, fragmented mtDNA is one of the most important mitochondrial DAMPs (mtDAMPs) associated with the regulation of innate immunity. $\mathrm{N}$-formyl peptides, ATP, the mitochondrial transcription factor TFAM, the mitochondrial specific phospholipid cardiolipin, reactive oxygen species (ROS) and other mitochondrial derived messengers also behave as mtDAMPs. In moderation, these mitochondrial-derived factors also serve as important intracellular second messengers, signalling to the rest of the cell in a retrograde fashion to ensure survival and adaptation. Such processes have a symbiotic co-dependency on the nuclear genome and serve to regulate homeostatic processes from cell death and antioxidant signalling to inflammatory cascades.

Mitochondrial function and ageing are intricately linked; however, this relationship is complex. Mitochondrial function and ROS production are considered to be important modulators of lifespan and mitochondrial biogenesis and turnover are important for slowing down the ageing process. In general, with ageing, homeostatic mitochondrial processes decline or become dysfunctional; whereby mitochondria exhibit structural abnormalities, reduced biogenesis, increased mtDNA mutations and less ETC capacity and ATP production [7,8]. Conversely, mild impairment of mitochondrial function may extend lifespan in yeast, worms and mice supporting a role for mitohormesis in longevity [9]. While the contribution of both mitochondria and ageing to the pathogenesis of acute and chronic lung diseases have been elegantly appraised by many before [7, 10-12], this review serves as an update for the lung community on the ever-increasing importance of the mitochondrion in lung ageing and disease. Lung ageing is accompanied by unique pathobiological changes that lead to functional, mechanical and structural alterations in the lung [13], yet how mitochondria contribute to these phenomena is an ever-evolving question. Importantly, lung diseases such as COPD, idiopathic pulmonary fibrosis (IPF), cancer or acute respiratory distress syndrome (ARDS) occur more frequently and with greater severity in older populations when compared to younger individuals [14-16].

To distinguish this review from others, we have focused our attention on the role of the mitochondrion in different sub-populations of cells in the lung and their related diseases. With the arrival of single cell sequencing and other sophisticated technologies, our characterisation and understanding of individual lung cell populations in the lung is just beginning. As the majority of mammalian cells rely on the mitochondrion for energy derivatives and/or metabolites, we will continue to uncover distinctive roles for this unfathomable organelle in ageing as well as in lung biology and disease. From ciliated epithelial cells to endothelial cells of the lung microvasculature, this review will discuss the importance of mitochondrial biology to specific specialised cellular functions (figure 1), as well as dissecting what ensues when mitochondrial-regulated critical processes inside these cells become dysfunctional.

\section{Diseases of the trachea, bronchi and bronchioles}

Luminal surfaces of the trachea, bronchi, and bronchioles are predominantly lined with a ciliated pseudostratified columnar epithelium intertwined with secretory goblet cells and lined by basal epithelial cells. Their combined mucociliary function is to secrete and move mucus along with foreign particles and pathogens out of the airways, a process that is sensitive to ageing [17-19]. Mitochondria with highly folded cristae and a dense matrix are abundant among the ciliary rootlets in apical regions of ciliated epithelial cells and are crucial for ciliary beating and mucociliary function [20]. Upon branching into the respiratory bronchioles, the epithelium acquires a simple cuboidal structure with the appearance of 


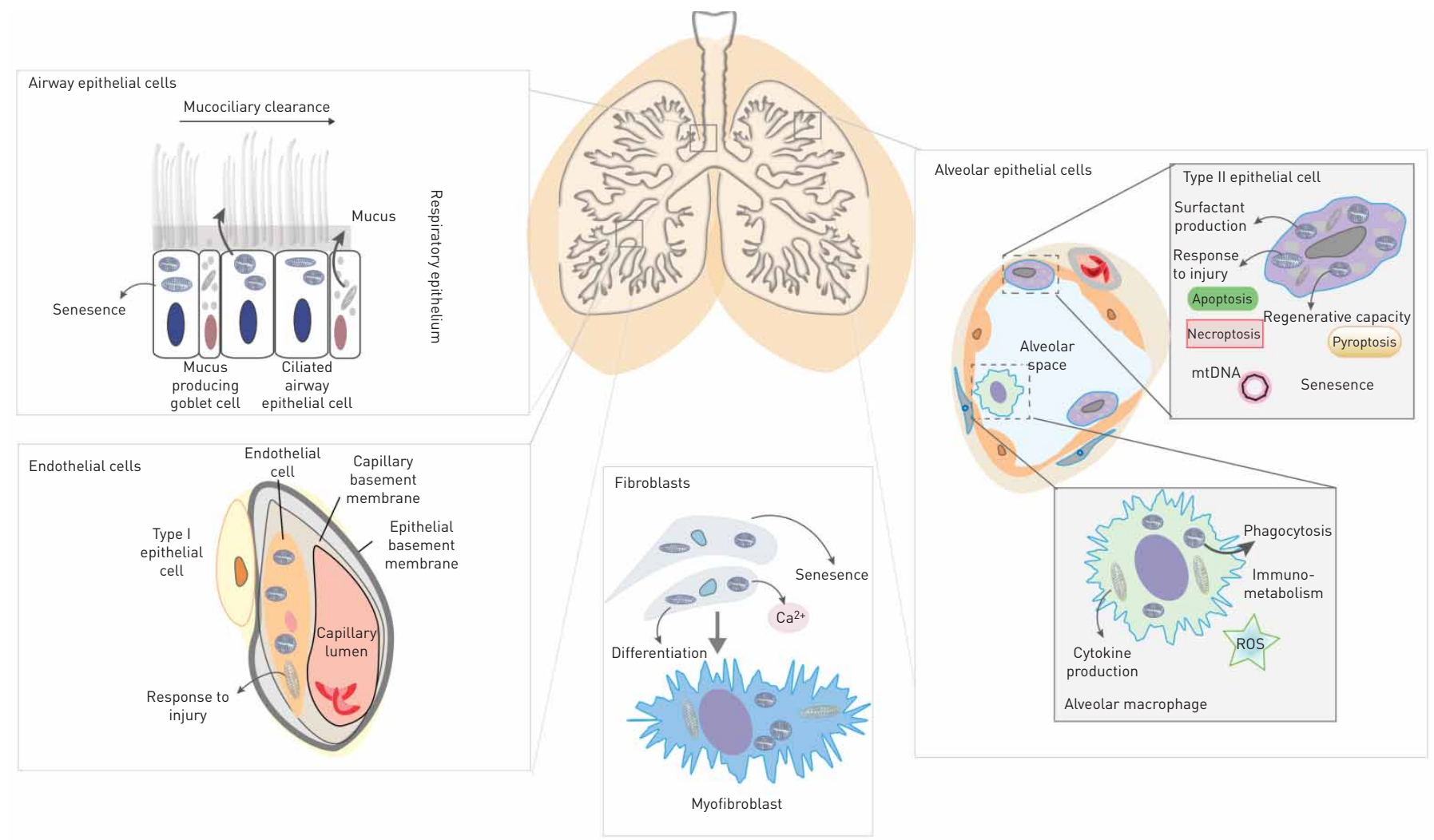

FIGURE 1 Mitochondria as regulators of cellular homeostasis in the lung. Mitochondria are important for the correct functioning of a number of well characterised and specialised lung cells. Mitochondria regulate mucociliary function, mucus secretion and senescence in airway epithelial cells. A number of important pathways in alveolar type two epithelial cells are regulated by the mitochondrion including surfactant production, senescence, programmed cell death and regeneration. Alveolar macrophages as well as other immune cells utilise the mitochondrion to respond to infection and release mitochondrial-related danger signals (damage-associated molecular patterns). Phagocytosis and immune-metabolic shifts in immune cell polarisation are also dependent on the mitochondrion. Differentiation of fibroblasts to myofibroblasts involves the up-regulation of a number of mitochondrial pathways and proteins and endothelial cells utilise the mitochondrion to responds to injury. ROS: reactive oxygen species.

non-ciliated club cells. Goblet, basal and club cells display relatively low densities of mitochondria distributed throughout the cytoplasm at baseline but this may change in response to injury and little is known about how mitochondria contribute to their specialised functions [21]. Similarly, ageing reduces tracheal epithelial thickness and decreases the number of tracheal basal stem cells which may be independent to the numbers of mitochondria in these cells [22]. Mitochondria in cells of the trachea, bronchi and bronchioles have been implicated in a number of diseases as discussed in detail below.

\section{Asthma}

Asthma is the most common chronic disease of the respiratory system and is characterised by inflammation, bronchial hyperresponsiveness (BHR) and remodelling of the bronchus [23]. Mitochondria have been associated with each of the above pathobiological features of asthma. Mitochondrial changes are observed in remodelled lung epithelium of a rat model of asthma [24] and in a murine ovalbumin model of asthma and have generally been associated with a loss in mitochondrial-related ATP production. However, the relationship between mitochondrial activity and BHR is debated with increased BHR correlating with a decline in the activity of cytochrome c oxidase (COX) subunit III and depletion of ATP [25], yet inhibition of COX42 subunit impairs ATP generation and reduces BHR [26]. ETC complex III dysfunction in mast cells also leads to enhanced histamine and serotonin secretion upon cell ragweed pollen extract exposure [27]. Conversely, mitochondrial dysfunction has largely and extensively been documented in bronchial smooth muscle (BSM) remodelling. The behaviour and proliferation of airway smooth muscle (ASM) cells are dependent on mitochondrial activity and contribute to the pathogenesis of asthma by secreting pro-inflammatory cytokines and other mediators [28]. In general, heightened mitochondrial mass and function associate with more BSM remodelling in asthma. Some specific examples include: increased expression of ATP5b of complex V of the ETC stimulates ASM cell proliferation and thickening in a murine model of asthma [29]; increases in mitochondrial mass are observed in the BSM of both severe [30] and mild asthmatic patients [31]; 
mitochondrial mass positively correlates with BSM surface area and clinical outcomes such as rate of exacerbation in asthma patients [30,31]; in severe asthmatic patients increases in mitochondrial mass are associated with increased mitochondrial biogenesis induced by abnormal calcium homeostasis [30]. In addition, Bnip3, a member of Bcl-2 family, which regulates mitochondrial function is overexpressed in asthmatic BSM cells and also participates in BSM cells proliferation [32,33]. Similarly, increased myeloid cell mitochondrial fatty acid oxidation (FAO) modulates bronchial inflammation in asthma, whereby inhibiting FAO is associated with decreased inflammation and immune responses [34]. Whether or not these increased mitochondrial features are homeostatic and increased as a protective response or really driving disease pathogenesis remains to be fully determined. The role of mitochondria in the pathogenesis of asthma is therefore cell type specific and requires further thorough examination. Finally, the role of mitochondria in asthma may also implicate ageing mechanisms and accelerated cellular senescence. For example, increased number of senescence-associated- $\beta$-Gal positive fibroblasts has been observed [35] and could be targeted by senolytic drugs such as azithromycin [36] or metformin [37] that also improve major clinical features of asthma such as peak expiratory flow and severe asthma exacerbations. Likewise, restoring oxidative metabolism by stimulating more arginine metabolism in the bronchial epithelium may also have therapeutic relevance via inhibition of proinflammatory signalling and suppression of T-helper (Th)2 inflammation [38, 39].

\section{Cystic fibrosis}

Cystic fibrosis (CF) is a genetic pathology attributed to a mutation of the CFTR gene on chromosome 7 which results in an abnormality of chloride channels in mucus producing cells. This leads to chronic bacterial airway infection, prominent neutrophilic inflammation and excess thick mucus in the airways, which may lead to progressive bronchiectasis $[40,41]$. Mitochondria play an important role in CF physiopathology. CFTR-mutated tracheobronchial gland epithelial cells display decreased ETC activity associated with dysfunction in complex I [42]. In fibroblasts isolated from patients with CF decreased activity of complex I is associated with an increase in oxygen consumption and mitochondrial calcium $[43,44]$ and in human and murine lung epithelial cells is associated with increased ROS [45, 46]. Increased ROS further decreases complex I activity and as a result, a vicious cycle may ensue [47]. Such increases in ROS may also facilitate Pseudomonas aeruginosa colonisation of the airway epithelium, as well as inflammatory responses [48].The precise source of ROS in these studies is yet to be attributed to the mitochondrion and alternative mechanisms may also contribute to the observed increases in ROS, including a loss in glutathione and superoxide dismutase pathways [49, 50], impairment of PTEN/CF transmembrane conductance regulator complex formation [51] and increased NADPH oxidase activity [52]. While ROS clearly play a role in the pathogenesis of CF, the source of this ROS and the cell-specific production of ROS and whether targeting ROS for therapeutic benefit in CF remains to be elucidated.

\section{Diseases of the alveoli}

Alveoli, the basic units for gaseous exchange are lined by a thin squamous epithelial cell layer surrounded by extracellular matrix, vascular endothelial cells and capillaries. The alveolar epithelium is composed of alveolar type 1 (AEC1) and alveolar type 2 (AEC2) epithelial cells. AEC2 cells are highly specialised, metabolically active secretory progenitor cells that contain significantly more mitochondria compared to their AEC1 counterparts [53-55]. AEC1 cells function as a gas exchange surface as well as maintaining the permeability barrier function of the alveolar membrane. Ageing is associated with a reduction in the lung elastic recoil, which may be associated with loss of alveolar epithelial surface area [56]. Alveolar size, widening of alveolar ducts and late alveolarisation all decline in murine ageing lungs; however, the absolute number of AEC2 cells in the alveolus appears to be relatively stable with ageing [13]. In lung parenchymal cells, ageing reduces mitochondrial number and function and increases ROS levels [22]. Similarly, the number of enlarged fused mitochondria increases with ageing in AEC2 cells [7] and AEC2 cells are predisposed to age-related mitophagy dysregulation which may directly affect their regenerative capacity [57]. In AEC2 cells mitochondrial biogenesis driven by the mammalian target of rapamycin/peroxisome proliferator-activated receptor- $\gamma$ complex $1 \alpha / \beta$ $(\mathrm{mTOR} / \mathrm{PGC}-1 \alpha / \beta)$ axis is upregulated in senescent lung epithelial cells [58]. Surfactant production and secretion by AEC2 cells is reliant on the mitochondrion $[59,60]$ and in response to injury, AEC2 differentiate into AEC1 cells concomitantly reducing the number and size of mitochondria [61,62]. Similarly, while alveolar endothelial cells contain less mitochondria than AEC2 cells, they also require functional mitochondria to respond to injury $[63,64]$. Mitochondria also play a key role in the correct functioning of immune cells in the alveoli, including alveolar macrophages, $\mathrm{CD}^{+} \mathrm{Th} 2$ and $\mathrm{CD}^{+}$(T-cytotoxic) cells $[27,65-69]$. Mitochondria in cells of the alveoli have been implicated in a number of diseases as discussed in detail below.

COPD is a chronic inflammatory lung disease associated with cigarette smoking and other environmental exposures. Dysregulation of mechanisms controlling mitochondrial function are widely appreciated in COPD and have been comprehensively reviewed elsewhere [70, 71]. There is increasing recognition that 
COPD represents accelerated ageing of the lung with an accumulation of senescent cells, including airway epithelial cells, fibroblasts, endothelial cells and AEC2 cells [72]. It is likely that oxidative stress from cigarette smoking or biomass smoke exposure, as well as ROS generated by activated inflammatory cells in the lungs, are the major drivers of senescence in COPD patients [73]. Senescent cells are metabolically active and release a variety of inflammatory proteins described as senescence-associated secretory phenotype (SASP), including proinflammatory cytokines (tumour necrosis factor (TNF)- $\alpha$, interleukin (IL)-1, IL-6), chemokines (CXCL1, CXCL8, CCL2), proteases (matrix metalloproteinase (MMP)2, MMP9) and growth factors (transforming growth factor (TGF)- $\beta$, insulin-like growth factor-binding protein, vascular endothelial growth factor), all of which are increased in COPD lungs. COPD is associated with a loss of several anti-ageing molecules, of which sirtuin-1 is predominant [74]. Reduced sirtuin-1 provides a mechanism for accelerated ageing in COPD by increasing cellular senescence through the acetylation of many key regulatory proteins that are linked to ageing.

This accelerated ageing process is associated with marked mitochondrial dysfunction (figure 2), which contributes to the pathophysiology of the disease in several ways [10]. Repeated cell divisions result in progressive shortening of telomeres, which eventually activates the DNA damage response, leading to activation of $\mathrm{p} 53$, resulting in cell cycle arrest or cellular senescence. Telomere shortening also leads to mitochondrial dysfunction through the activation of p53 and through mammalian target of rapamycin (mTOR) signalling [75]. Activated p53 and mTOR signalling inhibit PGC-1 $\alpha$, a transcription factor that is a key regulator of mitochondrial function, which is reduced in COPD [58, 76]. Dysfunctional mitochondria generate mitochondrial ROS (mROS), which may further damage telomeres to accelerate senescence [77]. When cells are depleted of mitochondria by Parkin-mediated mitophagy, there is a

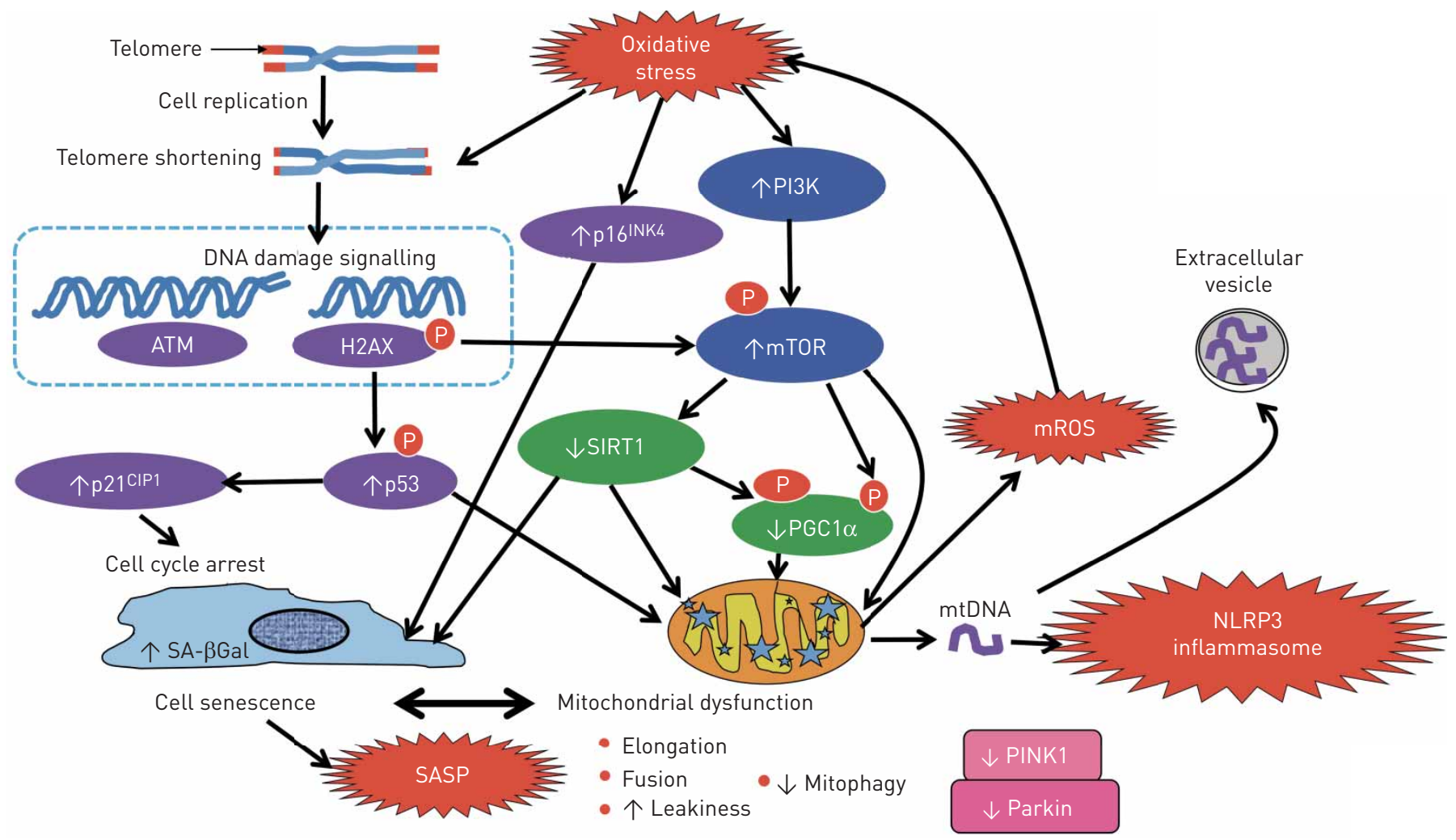

FIGURE 2 Mitochondrial dysfunction in COPD. Repeated cell division causes progressive telomere shortening which activates the DNA damage response, resulting in activation of p53, which activates the cyclic kinase inhibitor p21 ${ }^{\mathrm{CIP} 1}$, which puts the cell into cell cycle arrest or cellular senescence and also induces mitochondrial dysfunction. In COPD these effects are accelerated as oxidative stress causes further shortening and damage of telomeres, activates $\mathrm{p} 16^{\mathrm{INK} 4 a}$, which increase cellular senescence. Oxidative stress also activates phosphoinositide 3-kinase (PI3K), leading to activation of the key molecule mammalian target of rapamycin (mTOR), which further increases mitochondrial dysfunction by inhibiting peroxisome proliferator-activated receptor- $\gamma$ coactivator $1-\alpha(P G C-1 \alpha)$, a key regulator of mitochondrial biogenesis and function. mTOR also leads to a reduction in the anti-ageing molecule sirtuin-1 (SIRT1), which further inhibits PGC-1 $\alpha$ and mitochondrial function. Mitophagy is impaired in COPD so that damaged mitochondria accumulate in the cell as a result of reduced PTEN-inducible putative kinase-1 (PINK-1) and Parkin due to mTOR activation. Leaky mitochondria release mitochondrial reactive oxygen species (mROS), which are a major source of oxidative stress in COPD. Leaky mitochondria also release mitochondrial DNA (mtDNA), which may activate the NLRP3 inflammasome and also be released from the cell in extracellular vesicles. Senescent cells secrete a senescence-associated secretory phenotype (SASP) with multiple inflammatory proteins that are characteristically increased in COPD. 
reduction in cellular senescence and release of SASP mediators, indicating that mitochondria are important in driving senescence [78].

Mitochondria may be a major source of endogenous oxidative stress in COPD and therefore play a key role in driving its pathophysiology. ASM cells from COPD patients show abnormal metabolic activity with increased mROS generation at baseline and after exposure to inflammatory stimuli such as TNF- $\alpha$ and IL-1 $\beta$ and a reduction in ATP generation [79]. Similarly, ASM cells treated with cigarette smoke extract have impaired mitochondrial fission/fusion which may control ASM proliferation [80, 81]. Mitochondria show abnormal morphology in COPD cells, with increased mitochondrial mass, fragmentation, branching and loss of cristae [76]. This is mimicked in airway epithelial cells by cigarette smoke exposure in vitro, which also increased markers of senescence and SASP secretion [5, 76, 82]. These morphological mitochondrial abnormalities may reflect a reduction in PGC- $1 \alpha$, a key regulator of mitochondrial biogenesis, which is regulated by sirtuin- 1 and may also be due to dysregulation of mitophagy [5, 83-85]. Importantly, impaired mitophagy is linked to senescence in small airway epithelial cells and fibroblasts [84].

Increased mitochondrial iron may also contribute to mitochondrial dysfunction in COPD patients [86]. Defective mitochondrial function in macrophages from COPD patients may contribute to the characteristic defect in bacterial phagocytosis that may underlie bacterial colonisation of the lower airways in COPD patients [65-67]. Mitochondrial damage may release mtDNA, which is able to activate the NLRP3 inflammasome and release IL-1 $\beta$, which is increased in COPD [87-89] and mtDNA also activates the cytosolic DNA sensor cyclic guanosine monophosphate-adenosine monophosphate synthase, which results in activation of innate immunity and the secretion of interferons, which are also increased in COPD [90]. In an epithelial cell line, oxidative stress releases mtDNA in extracellular vesicles which may be taken up by untreated epithelial cells resulting in the release of IL-6 [91]. Increased mtDNA has been detected in the urine of COPD patients and correlates with some markers of disease severity [92]. Mitochondrial dysfunction may also contribute to the skeletal muscle weakness that is commonly found in COPD patients [93]. Overall there is accumulating evidence that mitochondrial dysfunction plays a key role in the pathogenesis of COPD and therefore may be a target for future therapies [70].

\section{Lung cancer}

Lung cancer is the most common cause of cancer-related death in men and the second most common in women. Smoking is the causal mechanism in $85 \%$ of lung cancers. It has long been recognised that cancer cells preferentially produce ATP by glycolysis rather than by mitochondria-mediated oxidative phosphorylation as in normal cells (Warburg effect). This metabolic shift leads to increased glucose uptake which leads to increased DNA and protein synthesis though increased generation of nucleic acids and amino acids. This suggests that mitochondrial dysfunction may play an important role in carcinogenesis and somatic mutations of mitochondrial genes are common in many types of cancer, including lung cancers [94]. Mutations of mtDNA are reported in lung cancer [95-97]. Cigarette smoke exposure may lead to damage and mutation of mtDNA, which seems to be more susceptible to oxidative damage than genomic DNA [98].

There is a greatly increased incidence of lung cancers in patients with COPD and this may reflect common molecular pathways [99]. Mitochondrial dysfunction in COPD may be an important factor increasing the development and spread of lung cancers [100]. Cigarette smoke exposure may cause damage and mutations in DNA, including mtDNA, but this is normally repaired by different DNA repair mechanisms. However, in COPD patients some of these repair mechanisms may be defective, as a result of decreased sirtuin-1 [101]. Dysfunctional mitochondria may also contribute to the acceleration of lung cancer because of chronic inflammation induced by mROS release from damaged mitochondria and due to the SASP as a consequence of cellular senescence. The hypoxia in severe COPD patients activates hypoxia-inducible factor-1 $\alpha$, which is overexpressed in a high proportion of nonsmall cell lung cancer patients, potentially increasing the risk of metastasis through promotion of increased epithelial-mesenchymal transition factors [102]. Activation of NLRP3 inflammasome as a consequence of mitochondrial dysfunction may also promote the growth and spread of lung cancers [103]. Mitochondria have a clear pathogenic role in the development and progression of lung cancer; however, the mechanism surrounding this relationship remains to be extensively determined. For example, does mtDNA sequence contribute to tumorigenicity or will targeting mROS or other mitochondrial related SASP processes hold therapeutic promise?

\section{Pneumonia}

Bacterial and viral community-acquired pneumonia (CAP) is a leading cause of morbidity and death worldwide. CAP is a syndrome in which acute infection of the lungs involves fever, cough, sputum production, shortness of breath, physical findings of consolidation, and leukocytosis [104]. Streptococcus pneumoniae remains the most commonly identified bacterial source of CAP with Haemophilus influenzae, Staphylococcus aureus, Moraxella catarrhalis and Pseudomonas aeruginosa also being causative. During 
influenza outbreaks, influenza virus becomes the principal cause of CAP increasing susceptibility to secondary bacterial infection. Respiratory syncytial virus, parainfluenza virus, human metapneumovirus, adenovirus, coronavirus and rhinovirus have also been implicated in CAP [104]. Pneumonia, both bacterial and viral, is a leading cause of morbidity and age-adjusted death and accounts for the majority of hospitalisations in patients aged $>65$ years, suggesting ageing plays an important role in the progression of CAP [105].

Mitochondria have an important role to play in the above bacterial and viral infections. Loss of mitochondrial-derived ATP, dysregulated mitochondrial complex expression, enhanced oxidative stress, diminished antioxidant responses, and decreased numbers of healthy mitochondria have been observed in response to S. pneumoniae [106]. More intriguingly, mitochondria are often targeted by virulence factors during infection to promote bacterial or viral replication $[107,108]$. Pneumolysin, a major virulence factor of $S$. pneumoniae targets the mitochondria of AEC cells leading to metabolic and morphological changes involving host mitochondrial calcium influx, loss of mitochondrial membrane potential and release of mtDNA [109]. Similarly, S. pneumoniae-derived hydrogen peroxide promotes mtDNA leakage and mediates interferon- $\beta$ expression in lung macrophages $[109,110]$. S. aureus infection increases the mitophagy protein PINK1 and decreases the availability the mitochondrial specific phospholipid cardiolipin [111]. A number of influenza A virulence factors translocate to the mitochondrial inner membrane, interact with mitochondrial antiviral-signalling protein, regulate fission/fusion processes, accelerate mitochondrial fragmentation, induce mitophagy and hijack mitochondrial-derived NADPH, ultimately resulting in suppression of innate immune signalling pathways [112-117]. Finally, age-associated deterioration in mitochondrial ATP, oxidative stress and antioxidant responses in macrophages also increase susceptibility to S. pneumoniae infection [106]. From the above studies it is clear that mitochondrial responses are essential for the response of the host to infection but how to therapeutically support and sustain mitochondrial function in the context of infection remains an open-ended question.

\section{Tuberculosis}

Tuberculosis is the leading cause of death in the world among infectious diseases [118]. Mycobacterium tuberculosis, the aetiologic agent, is transmitted via inhalation of droplets which are readily phagocytised by innate immune cells in the lung, yet only a fraction of infected persons show disease symptoms [119, 120]. Aging is a major risk factor for M. tuberculosis infection [121]. Similar to S. pneumoniae, M. tuberculosis targets mitochondria to enhance bacterial replication. One way is altering cellular death pathway in alveolar macrophages. Mitochondria play a vital role in apoptosis. With unclear mechanism, M. tuberculosis promotes necrosis and inhibits apoptosis upon infection [122]. M. tuberculosis contains tuberculosis necrotising toxin (TNT), a secreted nicotinamide adenine dinucleotide (NAD+) glycohydrolase, that induces necrosis in infected macrophages. TNT has been shown to activate key mediators of necroptosis RIPK3 and MLKL pathway [123]. In addition, M. tuberculosis damages the mitochondrial membrane upon infection and promotes release of cytochrome $\mathrm{c}$ from the intermembrane space, further promoting necrosis. Virulent M. tuberculosis inhibits crosslinking of annexin 1 and inhibits the formation of the apoptotic envelope [124]. Ageing inhibits the normal response of host alveolar macrophages to M. tuberculosis [125] and $M$. tuberculosis also induces a shift from oxidative phosphorylation to aerobic glycolysis and depresses the rate of mitochondrial respiration in macrophages. It also depresses the rate of glycolysis and OXPHOS to enter a state of metabolic quiescence and consequently decreases the rate of ATP production of the macrophage [126, 127]. In a similar manner to other bacteria, M. tuberculosis manipulates host mitochondrial homeostasis for its own benefit; how to therapeutically support and sustain mitochondrial function in the context of $M$. tuberculosis infection requires further attention.

\section{Critical care illness}

Acute lung injury (ALI), ARDS and sepsis are all associated with high morbidity and mortality in the critically ill patient population [67]. ALI is associated with the rapid onset of bilateral pulmonary infiltrates and hypoxaemia of noncardiac origin and is associated with sepsis, hyperoxia, trauma, pharmacological or xenobiotic exposures, and mechanical ventilation [128]. ALI and ARDS result from an aberrant inflammatory response of the lung with older patients at a significantly greater risk [129]. Diffuse alveolar damage, capillary congestion, atelectasis, intra-alveolar haemorrhage, alveolar oedema, hyaline-membrane formation, epithelial-cell hyperplasia, and interstitial oedema are all common histopathological features of ARDS [130, 131].

Bioenergetic dysfunction of mitochondria in the lung and skeletal muscle are a component of ARDS development [132]. mtDAMPs are higher in the bronchoalveolar lavage fluid (BALF) and circulation of individuals with sepsis and ARDS, as well as in experimental models [133-135]. Mitochondrial dysfunction is implicated in a number of animal models of ARDS (e.g. ventilator-induced lung injury (VILI) or hyperoxic-induced lung injury) and sepsis. Animals exposed to chronic hyperoxia have an 
increased number of swollen mitochondria with abnormal cristae [136]. Targeted depletion of fatty acid synthase FASN, a key enzyme in the synthesis of fatty acids, in AEC2 cells resulted in altered mitochondrial bioenergetics and more severe lung injury with hyperoxic exposure [137]. Similarly, VILI is associated with mitochondria damage, mitophagy, release of mtDNA and impaired FAO [138-140]. Mitochondrial dysfunction along with increased release of mtDAMPS, mitophagy and increased biogenesis have also been observed in a number of experimental sepsis models including Staphylococcus aureus- and LPS-induced sepsis [141-145]. Mitochondrial regulation in macrophages also plays an important role in the pathobiology of ALI, ARDS and sepsis with mitochondrial proteins regulating innate immune responses, including caspase-1 activation and phagocytic activity [146-148]. To summarise, loss of mitochondrial integrity and function is a common pathobiological theme in critical care illness. Whether or not this loss of integrity and consequent release of mtDAMPs into the extracellular space and /or circulation is a selective and programmed mechanism or merely a by-product of cell death/injury remains to be fully evaluated.

\section{Cells of the interstitium}

The pulmonary interstitium predominantly consists of the alveolar epithelium, pulmonary capillary endothelium, basement membrane, fibroblasts and perivascular and perilymphatic tissues. Quiescent elongated fibroblasts found in the interstitium regulate extracellular matrix remodelling and the repair following injury through agonist-dependent (e.g. TGF- $\beta$ ) transformation into myofibroblasts. Contractile myofibroblasts produce extracellular matrix proteins and can remodel tissues through the expression of $\alpha$-smooth muscle actin (SMA). Cellular senescence, a classic signature of the ageing process, plays an important role in lung fibroproliferative disorders. Disease-related changes in fibroblast behaviour rely on the upregulation of a number of key mitochondrial processes and the transformation of fibroblasts to myofibroblasts is accompanied by an increase in functioning mitochondrial content, activation of the mitochondrial stress response pathway via the transcription factor ATF4, as well as increases in glycolysis and mitochondrial biogenesis [149-152].

IPF

IPF is an irreversible progressive interstitial lung disease characterised by excessive formation of scar tissue in lungs and destruction of alveolar structure and pulmonary interstitium [153]. The exact aetiology remains unknown, however it is considered to be a disease of ageing whereby a genetically susceptible individual incurs AEC injury or damage, which in turn results in the activation and proliferation of myofibroblasts that secrete excessive extracellular matrix, driving abnormal lung architecture and gaseous exchange [154]. Age-associated changes in mitochondrial function may promote IPF development and progression [7] and fibroblasts and AT2 cells from IPF patients have senescent like phenotypes [155, 156].

Dysregulation of mechanisms controlling mitochondrial function are widely appreciated in IPF and have been comprehensively reviewed recently elsewhere [7, 157]. Briefly, mitochondrial dysfunction is evident in AEC2 cells of individuals with IPF $[57,59,158]$ and extracellular mtDNA is detected in the BALF and plasma of these individuals [159]. Experimental models of IPF demonstrate extensive mitochondrial-related in injury in AEC2 cells of the lung $[57,59,158,160,161]$. Targeted induction of mitochondrial damage in AEC2 cells via depletion of mitochondrial fusion results in spontaneous fibrosis, loss of the mitophagy regulator PINK1 or the mitochondrial-regulating transcription factor NRF2 promotes experimental fibrosis which may be age dependent, whereas loss of the mitochondrial protein phosphoglycerate mutase family member 5 (PGAM5) reduces lung fibrosis $[57,59,158,160,162]$. Inhibition of the mTORC1 complex with rapamycin restores mitochondrial homeostasis and reduces cellular senescence to bleomycin in lung epithelial cells [58].

Whether or not mitochondrial-associated injury in AEC2 cells directly regulates the activation and proliferation of myofibroblasts remains to be determined. However, a recent study has suggested that extracellular mtDNA which is found to be higher in the BALF of individuals with IPF may play a role in $\alpha$-SMA expression and metabolic changes in response to TGF- $\beta 1$ in normal human lung fibroblasts [159]. Mitochondrial related calcium changes may also regulate fibroblast to myofibroblast differentiation [163], which is consistent with fibroblasts from IPF lung fibroblasts having reduced mitochondrial mass, disrupted membranes, and altered cristae and oxygen consumption [155]. The master mitochondrial biogenesis regulator PGC1 $\alpha$ is stably repressed in IPF fibroblasts and in fibroblasts isolated from mice treated with bleomycin; an effect that is restored prior to fibrosis resolution in young but not aged mice [164]. TGF- $\beta$-induced glycolysis and mitochondrial oxygen consumption in human lung fibroblasts requires mTORC1 [165]. Finally, mitochondria in alveolar macrophages from IPF patients display prominent morphological defects with lower expression of PINK1, PARK2 and NRF1, however loss of mitophagy in macrophages in murine models of fibrosis is anti-fibrotic [166, 167]. The above studies demonstrate that a number of these highly conserved homeostatic mitochondrial pathways have distinctive 
TABLE 1 Potential mitochondrial targeting treatments for lung diseases

Disease

Cell target

Therapeutic compounds

Mitochondrial target

Model

Main finding

Asthma

Smooth
muscle cell
Macrophage

Gallopamil

Etomoxir

Fibroblast

NA

NA

NA

NA

NA

PAH

NA

NA

NA

NA

NA

injury

Alveolar

epithelial cell

NA

Epithelial cell NA

Epithelial cell

Epithelial cell

IPF

Alveolar
epithelial cell
Alveolar

epithelial cell

Fibroblast

Alveolar epithelial cell

Azithromycin

Metformin

Rapamycin

Resveratrol

L-arginine

Metformin

Rapamycin

MitoQ

Mildronate

MitoTEMPO

MitoQ Sobetirome

Rapamycin
Roxithromycin

ROS production

Adaptive mitochondrial

biogenesis and

mitophagy stimulation

NA

mesenchymal stem cells

mitochondria transfer

Fusion protein targeting the DNA repair enzyme 8-oxoguanine-DNA glycosylase

1 to the mitochondria

Targeting dynein motor protein

Thyroid hormone mimetics

Genetic over expression of mitochondrial-targeted catalase

$$
\text { Carbon monoxide }
$$

Mitochondrial ROS

Carnitine synthesis Mitochondrial ROS

Mitochondrial ROS

Mitochondrial ROS

$$
\begin{gathered}
\text { Mitochondria } \\
\text { biogenesis }
\end{gathered}
$$

Mitochondrial ROS

Heme oxygenase

Mitochondrial biogenesis
Mouse

Mouse

Mouse

Human

Mouse

Human

Human

Rat

Mouse

Mouse

Mouse

Rat

Rat

Influenza A virus infected mouse

Human

Epithelial cells and mouse

Human

Epithelial cells

Mouse

Mouse

Mouse

Epithelial cells
Decrease of SMC mass and exacerbation rate

Decreased $\mathrm{TH}_{2}$ inflammation

Improved peak expiratory flow, symptoms and quality of life

Decreased severe exacerbations

Decreased airway remodelling

Decreased eosinophilic airway inflammation

Decreased fibrotic responses and airway inflammation

Decreased AHR and inflammation

Increased endothelial function and decrease arterial remodelling

Decreased pulmonary artery smooth muscle cell proliferation

Decreased right ventricular hypertrophy

Removes damaged mitochondria and increases tissue repair and cell survival

Restoration of alveolar bioenergetics and protection against LPS-induced ALI

Enhanced survival under ventilator-induced lung injury

Improves lung function

Reduction in lung inflammation, neutrophil infiltration, viral titre and mortality

Reduced epithelial RSV production and inflammation

Reduced epithelial RSV production and inflammation

Decreased bleomycin-induced pulmonary fibrosis

Decreased asbestos or bleomycin-induced pulmonary fibrosis

Decreased bleomycin-induced pulmonary fibrosis

Reduces mitochondrial biogenesis and cellular senescence in cultured alveolar epithelial cells 


\section{TABLE 1 Continued}

\begin{tabular}{|c|c|c|c|c|c|}
\hline Disease & Cell target & Therapeutic compounds & Mitochondrial target & Model & Main finding \\
\hline & Myofibroblast & Pirfenidone & $\begin{array}{l}\text { PARK2-mediated } \\
\text { mitophagy }\end{array}$ & Mouse and cells & $\begin{array}{l}\text { Inhibits lung fibrosis } \\
\text { development in the setting } \\
\text { of insufficient mitophagy }\end{array}$ \\
\hline \multicolumn{6}{|l|}{ COPD } \\
\hline & Macrophage & Carbon monoxide & Heme oxygenase & Human & $\begin{array}{l}\text { Reduced sputum eosinophilia } \\
\text { and improved methacholine } \\
\text { responsiveness }\end{array}$ \\
\hline & $\begin{array}{l}\text { Ciliated } \\
\text { epithelial cell }\end{array}$ & $\begin{array}{l}\text { Mdivi-1, a pharmacological } \\
\text { inhibitor of Drp1 }\end{array}$ & Mitophagy & Mice & $\begin{array}{l}\text { Restores mucociliary } \\
\text { dysfunction }\end{array}$ \\
\hline & Epithelial cell & MitoTEMPO & Mitochondrial ROS & $\begin{array}{l}\text { Human epithelial } \\
\text { cells }\end{array}$ & $\begin{array}{l}\text { Inhibition of cigarette smoke } \\
\text { extract induce mitochondria } \\
\text { fragmentation }\end{array}$ \\
\hline & $\begin{array}{l}\text { Endothelial } \\
\text { cell }\end{array}$ & $\begin{array}{c}\text { Mitochondria-targeted } \mathrm{H}_{2} \mathrm{~S} \\
\text { donors AP39, AP123 and RT01 }\end{array}$ & $\begin{array}{l}\text { Mitochondria proteins } \\
\text { persulfidation }\end{array}$ & $\begin{array}{l}\text { Human } \\
\text { endothelial cells }\end{array}$ & Decrease cellular senescence \\
\hline & $\begin{array}{l}\text { Mononuclear } \\
\text { blood cell }\end{array}$ & Rapamycin & mTOR pathway & $\begin{array}{l}\text { Human } \\
\text { peripheral blood } \\
\text { mononuclear } \\
\text { cells }\end{array}$ & $\begin{array}{l}\text { Restoring corticosteroid } \\
\text { sensitivity }\end{array}$ \\
\hline & NA & Deferiprone & $\begin{array}{l}\text { Mitochondrial iron } \\
\text { redistribution }\end{array}$ & Mouse & $\begin{array}{l}\text { Restoring mucociliary function, } \\
\text { inhibiting BAL infiltrates }\end{array}$ \\
\hline & NA & Resveratrol & Mitochondrial ROS & Mouse & $\begin{array}{l}\text { Delayed the loss of lung } \\
\text { compliance, maintained lung } \\
\text { structure and blocked } \\
\text { parenchymal cell DNA } \\
\text { damage }\end{array}$ \\
\hline & Epithelial cell & $\begin{array}{l}\text { Mitochondria-targeted } \\
\text { mito-lonidamine }\end{array}$ & $\begin{array}{c}\text { Oxidative } \\
\text { phosphorylation }\end{array}$ & $\begin{array}{l}\text { Human epithelial } \\
\text { cell line }\end{array}$ & $\begin{array}{l}\text { Improved mitochondrial } \\
\text { function and restores } \\
\text { autophagy } \\
\text { Metastasis reduction in } \\
\text { experimental lung tumours }\end{array}$ \\
\hline
\end{tabular}

PAH: pulmonary arterial hypertension; IPF: idiopathic pulmonary fibrosis; SMC: smooth muscle cell; TH: T-helper; NA: not addressed; ROS: reactive oxygen species; NO: nitric oxide; AHR: airway hyperreactivity; LPS: lipopolysaccharide; ALI: acute lung injury; RSV: respiratory syncytial virus; TGF: transforming growth factor; ASM: airway smooth muscle; HSMC: human smooth muscle cells; mTOR: mammalian target of rapamycin.

functions that are cell type specific highlighting the complexities of targeting these pathways for therapeutic benefit in IPF.

\section{Vascular endothelial cells}

The lung microvasculature is an evolutionarily conserved system consisting of a dense network of capillaries that line the branched airways, alveolar ducts and alveoli. This expansive capillary surface is covered by a thin layer of capillary endothelial cells. Delicate alveolar-capillary membrane interactions involving precise epithelial-endothelial crosstalk mediate gaseous exchange, delivery of nutrients and regulation of immunosurveillance. Lung capillary endothelial cells are embedded within grooves of AT1 cells producing paracrine factors to stimulate the propagation of alveolar progenitor and mesenchymal cells, ultimately guiding regeneration and repair of the lung [168-170]. Ageing results in a loss in the density of pulmonary capillaries [171] and cellular senescence-elevated oxidative stress plays a role in age-associated vascular endothelial dysfunction [172]. Despite their close proximity to circulating oxygen 
and nutrients, endothelial cells oxidise only a minor fraction of glucose in their mitochondria, metabolising $90 \%$ of cellular glucose anaerobically to produce lactate, a phenomenon that appears to facilitate expansion of vascular networks during organ growth [173-175]. Endothelial cells have active mitochondria ( $5 \%$ of the cellular volume) and rely on their mitochondria for essential functions as hubs for second messenger signalling and in response to injury, however, the role of mitochondria in pulmonary capillary endothelial cells has not been extensively investigated $[63,64,176]$.

\section{Pulmonary arterial hypertension}

Mitochondrial dysfunction is associated with pulmonary arterial hypertension (PAH), an incurable disease characterised by pulmonary arterial endothelial cell apoptosis, decreased microvessels and occlusive vascular remodelling [177]. PAH is characterised by increased pulmonary arterial pressure associated with remodelling of the pulmonary arteries that may in turn lead to right ventricular hypertrophy increasing the risk of right heart failure and death [178]. Mitochondrial dysfunction has been described in endothelial cell and pulmonary arterial smooth muscle cells (PASMC) of individuals with PAH and mitochondrial ETC dysfunction associated with a metabolic shift towards increased glycolysis has also been observed [179-181]. PAH-PASMCs display increased expression of ENO1, a key enzyme in glycolysis, leading to a shift away from mitochondrial oxidative phosphorylation in favour of glycolysis [182]. Similarly, PAH-endothelial cells have increased glucose uptake in parallel to diminished oxygen consumption [179]. PDH, the enzyme permitting the entry of pyruvate into mitochondria, is decreased in PAH-endothelial cells and PAH-PASMC [179, 183]. Metabolic shifts toward increased glycolysis in PAH-PASMC are also associated with a loss in activity of

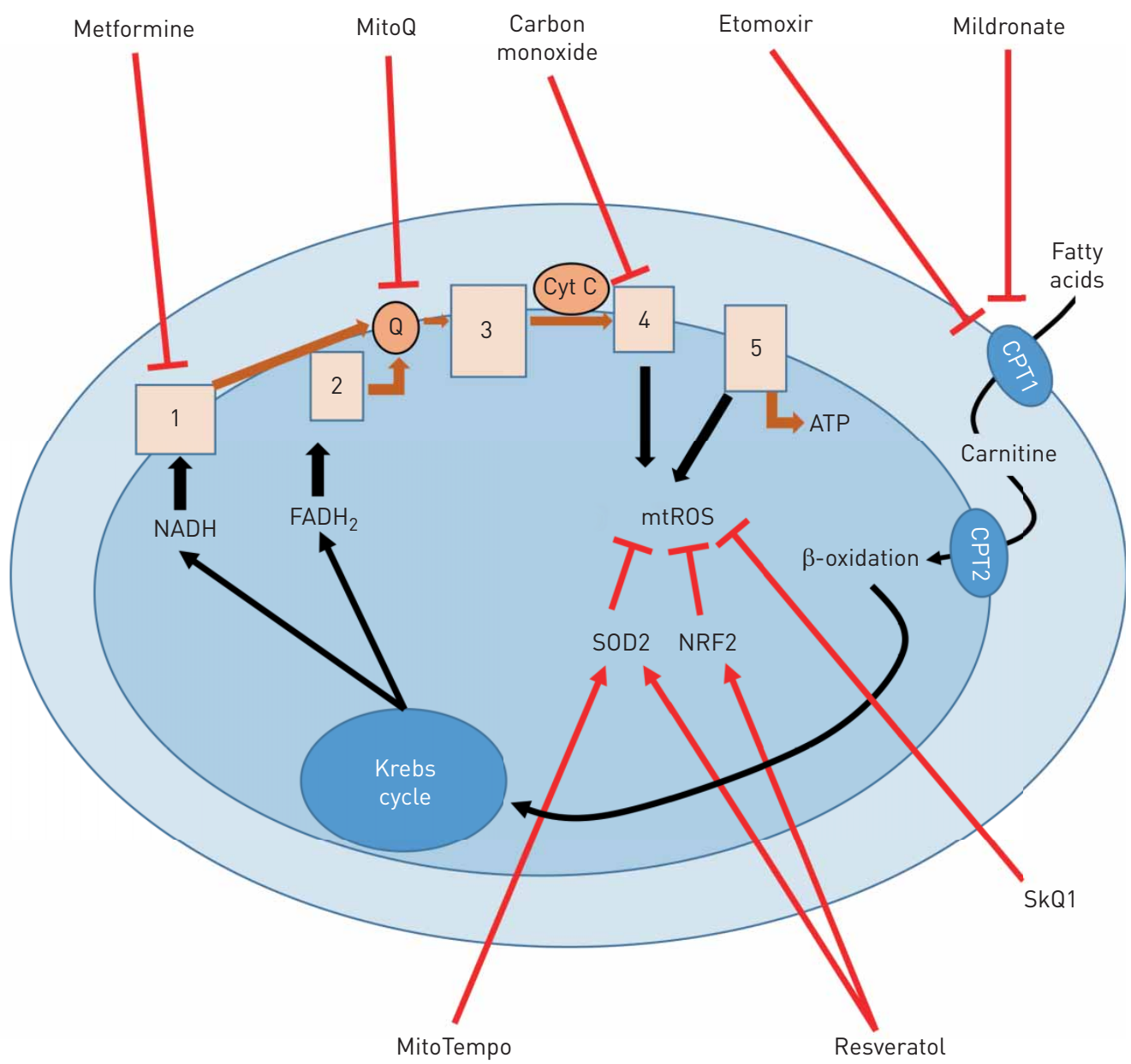

FIGURE 3 Schematic diagram of drugs targeting mitochondria developed in lung disease. Red arrows/lines represent the activation/inhibition site of action of drugs. NADH: nicotinamide adenine dinucleotide; FADH: flavin adenine dinucleotide; ATP: adenosine triphosphate; SOD2: superoxide dismutase 2; NRF2: nuclear factor erythroid-2-related factor; mtROS: mitochondrial reactive oxygen species; CPT: carnitine palmitoyltransferase; Q: ubiquinone/ubiquinol; Cytc: cytochrome c. 
complex I and III of the ETC [184-186]. Since disruption of ETC is an important contributor to mROS release, the absence of oxygen consumption may lead to a retrograde accumulation of electrons and generation of superoxide production in PAH-PASMC $[187,188]$. Such an increase of mROS also activates ageing pathways. Ageing is an important risk factor for cardiovascular disease and senescence has been implicated in the development or aggravation of PAH [189]. ROS production is associated with DNA damage leading to PAH-endothelial cell and PAH-PASMC cell cycle arrest [190]. Moreover, pro-inflammatory SASP is increased in PAH [189]. Interestingly, modulation of SASP expression with mitochondrial drugs such as metformin has been shown to inhibit SASP expression and prevent PAH [191, 192]. Also, rapamycin, interferes with the development of PAH reducing SASP and PAH-PASMC remodelling [193]. To summarise metabolic switching to glycolysis has been identified as an important pathobiological feature in PAH-endothelial cells and PAH-PASMCs; however, whether or not this process is a pathogenic or protective response and how this relates to the generation of ROS and mROS remains to be investigated.

\section{Conclusion}

Mitochondrial dysfunction is a hallmark of ageing and is observed in the majority of acute and chronic lung diseases. However, as this review highlights, a significant amount of these ground-breaking studies infer conclusions from whole lung experimental systems (global deletion of a gene rather than targeted deletion in cell types) or in vitro models. In the past 5 years we are beginning to appreciate the opposing and diverse responsibilities that many central mitochondrial proteins have in specialised cells of the lung and this is a rapidly evolving field. Fortunately, as the awareness of this essential organelle in disease pathology has increased, a demand for new approaches to measure mitochondrial function and metabolites has resulted in the development of new forms of microscopy and spectroscopy that open windows into previously unknown aspects of mitochondrial biology. Marrying these technologies with the isolation of pure and distinct lung cell populations will expand our knowledge even further, allowing us to better explore the feasibility of targeting the mitochondrion for therapy in lung disease. At the time of writing, a number of potential mitochondrial pathways have already been proposed for promising therapeutic exploration (table 1). From the use of senolytics to reverse senescence, to stimulating mitochondrial biogenesis and mitophagy [143], to mitochondrial transplantation approaches to repair the injured alveolar epithelium [194], to targeting mROS [195, 196] or stimulating mitohormesis with carbon monoxide (figure 3) [197], an array of promising pre-clinical studies may provide opportunities to deliver mitochondrial-based therapeutics to the bedside to treat acute and chronic lung disease. However, until we uncover more about the distinctive functions of mitochondria in individual lung cell populations, we must proceed with cautious enthusiasm.

Conflict of interest: S.M. Cloonan has nothing to disclose. K. Kim has nothing to disclose. P. Esteves has nothing to disclose. T. Trian has nothing to disclose. P.J. Barnes reports grants and personal fees from AstraZeneca and Boehringer Ingelheim, during the conduct of the study; and personal fees from Novartis, Pieris and EpiEndo, outside the submitted work;

Support statement: The authors acknowledge support from the US National Institute of Health grant R00-HL125899 (S M. Cloonan), Science Foundation Ireland grant FRL4862 (S.M. Cloonan), the Fondation pour la Recherche Médicale grant DEQ20170336706 (T. Trian and P. Esteves.) and the Agence Nationale pour la Recherche grant ANR, ROSAE project CE14-0015-01 (T. Trian and P. Esteves).

\section{References}

1 Mishra P, Carelli V, Manfredi G, et al. Proteolytic cleavage of Opal stimulates mitochondrial inner membrane fusion and couples fusion to oxidative phosphorylation. Cell Metab 2014; 19: 630-641.

2 Toyama EQ, Herzig S, Courchet J, et al. Metabolism. AMP-activated protein kinase mediates mitochondrial fission in response to energy stress. Science 2016; 351: 275-281.

3 Mishra P, Chan DC. Mitochondrial dynamics and inheritance during cell division, development and disease. Nat Rev Mol Cell Biol 2014; 15: 634-646.

4 Kovarova M, Hesker PR, Jania L, et al. NLRP1-dependent pyroptosis leads to acute lung injury and morbidity in mice. J Immunol 2012; 189: 2006-2016.

5 Mizumura K, Cloonan SM, Nakahira K, et al. Mitophagy-dependent necroptosis contributes to the pathogenesis of COPD. J Clin Invest 2014; 124: 3987-4003.

6 Schumacker PT, Gillespie MN, Nakahira K, et al. Mitochondria in lung biology and pathology: more than just a powerhouse. Am J Physiol Lung Cell Mol Physiol 2014; 306: L962-L974.

7 Mora AL, Bueno M, Rojas M. Mitochondria in the spotlight of aging and idiopathic pulmonary fibrosis. $J$ Clin Invest 2017; 127: 405-414.

8 Fahn HJ, Wang LS, Hsieh RH, et al. Age-related 4,977 bp deletion in human lung mitochondrial DNA. Am J Respir Crit Care Med 1996; 154: 1141-1145.

9 Sahin E, DePinho RA. Axis of ageing: telomeres, p53 and mitochondria. Nat Rev Mol Cell Biol 2012; 13 : 397-404.

10 Birch J, Barnes PJ, Passos JF. Mitochondria, telomeres and cell senescence: implications for lung ageing and disease. Pharmacol Ther 2018; 183: 34-49. 
Cho SJ, Stout-Delgado HW. Aging and lung disease. Annu Rev Physiol 2020; 82: 433-459.

Cloonan SM, Choi AM. Mitochondria in lung disease. J Clin Invest 2016; 126: 809-820.

Schulte H, Mühlfeld C, Brandenberger C. Age-related structural and functional changes in the mouse lung. Front Physiol 2019; 10: 1466.

Ito K, Barnes PJ. COPD as a disease of accelerated lung aging. Chest 2009; 135: 173-180.

Crit Care Med 2006; 174: 810-816.

Rubenfeld GD, Caldwell E, Peabody E, et al. Incidence and outcomes of acute lung injury. N Engl J Med 2005; 353: 1685-1693.

Janssens JP, Pache JC, Nicod LP. Physiological changes in respiratory function associated with ageing. Eur Respir J 1999; 13: 197-205.

Bailey KL, Kharbanda KK, Katafiasz DM, et al. Oxidative stress associated with aging activates protein kinase C $\varepsilon$, leading to cilia slowing. Am I Physiol Lung Cell Mol Physiol 2018; 315: L882-L890.

Wansleeben C, Bowie E, Hotten DF, et al. Age-related changes in the cellular composition and epithelial organization of the mouse trachea. PLoS One 2014; 9: e93496.

Burkhalter MD, Sridhar A, Sampaio P, et al. Imbalanced mitochondrial function provokes heterotaxy via aberrant ciliogenesis. J Clin Invest 2019; 129: 2841-2855.

Hayashi T, Ishii A, Nakai S, et al. Ultrastructure of goblet-cell metaplasia from Clara cell in the allergic asthmatic airway inflammation in a mouse model of asthma in vivo. Virchows Arch 2004; 444: 66-73.

Hegab AE, Ozaki M, Meligy FY, et al. Calorie restriction enhances adult mouse lung stem cells function and reverses several ageing-induced changes. J Tissue Eng Regen Med 2019; 13: 295-308.

Fixman ED, Stewart A, Martin JG. Basic mechanisms of development of airway structural changes in asthma. Eur Respir J 2007; 29: 379-389.

Li J, Zhang YP, Zarei M, et al. A topical aqueous oxygen emulsion stimulates granulation tissue formation in a porcine second-degree burn wound. Burns 2015; 41: 1049-1057.

Mabalirajan U, Aich J, Leishangthem GD, et al. Effects of vitamin E on mitochondrial dysfunction and asthma features in an experimental allergic murine model. J Appl Physiol 2009; 107: 1285-1292.

Huttemann M, Lee I, Gao X, et al. Cytochrome c oxidase subunit 4 isoform 2-knockout mice show reduced enzyme activity, airway hyporeactivity, and lung pathology. FASEB J 2012; 26: 3916-3930.

Chodaczek G, Bacsi A, Dharajiya N, et al. Ragweed pollen-mediated IgE-independent release of biogenic amines from mast cells via induction of mitochondrial dysfunction. Mol Immunol 2009; 46: 2505-2514.

Delmotte P, Zavaletta VA, Thompson MA, et al. TNFo decreases mitochondrial movement in human airway smooth muscle. Am J Physiol Lung Cell Mol Physiol 2017; 313: L166-L176.

Zuo J, Lei M, Wen M, et al. Overexpression of ATP5b promotes cell proliferation in asthma. Mol Med Rep 2017; 16: 6946-6952.

Trian T, Benard G, Begueret $\mathrm{H}$, et al. Bronchial smooth muscle remodeling involves calcium-dependent enhanced mitochondrial biogenesis in asthma. J Exp Med 2007; 204: 3173-3181.

Girodet PO, Dournes G, Thumerel M, et al. Calcium channel blocker reduces airway remodeling in severe asthma: a proof-of-concept study. Am J Respir Crit Care Med 2015: 191: 876-883.

Pan S, Shah SD, Panettieri RA Jr, et al. Bnip3 regulates airway smooth muscle cell focal adhesion and proliferation. Am J Physiol Lung Cell Mol Physiol 2019; 317: L758-L767.

Pan S, Sharma P, Shah SD, et al. Bitter taste receptor agonists alter mitochondrial function and induce autophagy in airway smooth muscle cells. Am J Physiol Lung Cell Mol Physiol 2017; 313: L154-L165.

Al-Khami AA, Ghonim MA, Del Valle L, et al. Fuelling the mechanisms of asthma: Increased fatty acid oxidation in inflammatory immune cells may represent a novel therapeutic target. Clin Exp Allergy 2017; 47: 1170-1184.

Hadj Salem I, Dube J, Boulet LP, et al. Telomere shortening correlates with accelerated replicative senescence of bronchial fibroblasts in asthma. Clin Exp Allergy 2015; 45: 1713-1715.

Gibson PG, Yang IA, Upham JW, et al. Effect of azithromycin on asthma exacerbations and quality of life in adults with persistent uncontrolled asthma (AMAZES): a randomised, doubleblind, placebocontrolled trial. Lancet 2017; 390: 659-668.

Wu TD, Keet CA, Fawzy A, et al. Association of metformin initiation and risk of asthma exacerbation. A claims-based cohort study. Ann Am Thorac Soc 2019; 16: 1527-1533.

$\mathrm{Xu}$ W, Ghosh S, Comhair SA, et al. Increased mitochondrial arginine metabolism supports bioenergetics in asthma. J Clin Invest 2016; 126: 2465-2481.

Mabalirajan U, Ahmad T, Leishangthem GD, et al. Beneficial effects of high dose of L-arginine on airway hyperresponsiveness and airway inflammation in a murine model of asthma. J Allergy Clin Immunol 2010; 125: 626-635.

Wainwright BJ, Scambler PJ, Schmidtke J, et al. Localization of cystic fibrosis locus to human chromosome 7cen-q22. Nature 1985; 318: 384-385.

Stoltz DA, Meyerholz DK, Welsh MJ. Origins of cystic fibrosis lung disease. N Engl J Med 2015; 372: 351-362.

Valdivieso AG, Marcucci F, Taminelli G, et al. The expression of the mitochondrial gene MT-ND4 is downregulated in cystic fibrosis. Biochem Biophys Res Commun 2007; 356: 805-809.

Shapiro BL, Feigal RJ, Lam LF. Mitochondrial NADH dehydrogenase in cystic fibrosis. Proc Natl Acad Sci USA 1979; 76: 2979-2983.

Feigal RJ, Shapiro BL. Mitochondrial calcium uptake and oxygen consumption in cystic fibrosis. Nature 1979; 278: $276-277$.

L'Hoste S, Chargui A, Belfodil R, et al. CFTR mediates cadmium-induced apoptosis through modulation of ROS level in mouse proximal tubule cells. Free Radic Biol Med 2009; 46: 1017-1031. cystic fibrosis through ROS-mediated autophagy inhibition. Nat Cell Biol 2010; 12: 863-875.

Cleeter MW, Cooper JM, Schapira AH. Irreversible inhibition of mitochondrial complex I by 1-methyl-4-phenylpyridinium: evidence for free radical involvement. J Neurochem 1992; 58: 786-789. 
Rimessi A, Bezzerri V, Patergnani S, et al. Mitochondrial Ca2+-dependent NLRP3 activation exacerbates the Pseudomonas aeruginosa-driven inflammatory response in cystic fibrosis. Nat Commun 2015; 6: 6201.

Gao L, Kim KJ, Yankaskas JR, et al. Abnormal glutathione transport in cystic fibrosis airway epithelia. Am J Physiol 1999; 277: L113-L118.

Rottner M, Tual-Chalot S, Mostefai HA, et al. Increased oxidative stress induces apoptosis in human cystic fibrosis cells. PLoS One 2011; 6: e24880.

Riquelme SA, Lozano C, Moustafa AM, et al. CFTR-PTEN-dependent mitochondrial metabolic dysfunction promotes Pseudomonas aeruginosa airway infection. Sci Transl Med 2019; 11: eaav4634.

de Bari L, Favia M, Bobba A, et al. Aberrant GSH reductase and NOX activities concur with defective CFTR to pro-oxidative imbalance in cystic fibrosis airways. J Bioenerg Biomembr 2018; 50: 117-129.

Massaro GD, Gail DB, Massaro D. Lung oxygen consumption and mitochondria of alveolar epithelial and endothelial cells. J Appl Physiol 1975; 38: 588-592.

Stone KC, Mercer RR, Gehr P, et al. Allometric relationships of cell numbers and size in the mammalian lung Am J Respir Cell Mol Biol 1992; 6: 235-243.

2013; 123: 3025-3036.

Subramaniam K, Kumar H, Tawhai MH. Evidence for age-dependent air-space enlargement contributing to loss of lung tissue elastic recoil pressure and increased shear modulus in older age. J Appl Physiol 2017; 123: 79-87.

Bueno M, Lai YC, Romero Y, et al. PINK1 deficiency impairs mitochondrial homeostasis and promotes lung fibrosis. J Clin Invest 2015; 125: 521-538.

Summer R, Shaghaghi H, Schriner D, et al. Activation of the mTORC1/PGC-1 axis promotes mitochondrial biogenesis and induces cellular senescence in the lung epithelium. Am J Physiol Lung Cell Mol Physiol 2019; 316: L1049-L1060.

Chung KP, Hsu CL, Fan LC, et al. Mitofusins regulate lipid metabolism to mediate the development of lung fibrosis. Nat Commun 2019; 10: 3390.

Walski M, Pokorski M, Antosiewicz J, et al. Pulmonary surfactant: ultrastructural features and putative mechanisms of aging. J Physiol Pharmacol 2009; 60 Suppl 5: 121-125.

Moriguchi K, Higashi N, Kitagawa S, et al. Differentiation of human pulmonary alveolar epithelial cells revealed by peroxisome changes in pulmonary proteinosis. Exp Mol Pathol 1984; 40: 262-270.

, Ogawa K. Cytochemical quantitation of cytochrome oxidase activity in rat pulmonary alveolar epithelia cells and possible defect in type I cells. J Electron Microsc (Tokyo) 1986; 35: 19-28.

Hough RF, Islam MN, Gusarova GA, et al. Endothelial mitochondria determine rapid barrier failure in chemical lung injury. JCI Insight 2019; 4: e124329.

Haslip M, Dostanic I, Huang Y, et al. Endothelial uncoupling protein 2 regulates mitophagy and pulmonary hypertension during intermittent hypoxia. Arterioscler Thromb Vasc Biol 2015; 35: 1166-1178.

O’Beirne SL, Kikkers SA, Oromendia C, et al. Alveolar macrophage immunometabolism and lung function impairment in smoking and chronic obstructive pulmonary disease. Am J Respir Crit Care Med 2020; 201: 735-739.

Bewley MA, Preston JA, Mohasin M, et al. Impaired mitochondrial microbicidal responses in chronic obstructive pulmonary disease macrophages. Am J Respir Crit Care Med 2017; 196: 845-855.

Belchamber KBR, Singh R, Batista CM, et al. Defective bacterial phagocytosis is associated with dysfunctional mitochondria in COPD macrophages. Eur Respir J 2019; 54: 1802244.

Buck MD, O'Sullivan D, Klein Geltink RI, et al. Mitochondrial dynamics controls T cell fate through metabolic programming. Cell 2016; 166: 63-76.

Pelgrom LR, Everts B. Metabolic control of type 2 immunity. Eur J Immunol 2017; 47: 1266-1275.

Baker J, Donnelly LE, Barnes PJ. Senotherapy: a new horizon for COPD therapy. Chest 2020; 158: 562-570.

Ryter SW, Rosas IO, Owen CA, et al. Mitochondrial dysfunction as a pathogenic mediator of chronic obstructive pulmonary disease and idiopathic pulmonary fibrosis. Ann Am Thorac Soc 2018; 15: S266-S272.

Barnes PJ, Baker J, Donnelly LE. Cellular senescence as a mechanism and target in chronic lung diseases. Am J Respir Crit Care Med 2019; 200: 556-564.

Kirkham PA, Barnes PI. Oxidative stress in COPD. Chest 2013; 144: 266-273.

Nakamaru Y, Vuppusetty C, Wada H, et al. A protein deacetylase SIRT1 is a negative regulator of metalloproteinase-9. FASEB J 2009; 23: 2810-2819.

Correia-Melo C, Passos JF. Mitochondria: are they causal players in cellular senescence? Biochim Biophys Acta 2015; 1847: 1373-1379.

Hoffmann RF, Zarrintan S, Brandenburg SM, et al. Prolonged cigarette smoke exposure alters mitochondrial structure and function in airway epithelial cells. Respir Res 2013; 14: 97.

Liu L, Trimarchi JR, Smith PJ, et al. Mitochondrial dysfunction leads to telomere attrition and genomic instability. Aging Cell 2002; 1: 40-46.

Correia-Melo C, Ichim G, Tait SW, et al. Depletion of mitochondria in mammalian cells through enforced mitophagy. Nat Protoc 2017; 12: 183-194.

Wiegman $\mathrm{CH}$, Michaeloudes $\mathrm{C}$, Haji $\mathrm{G}$, et al. Oxidative stress-induced mitochondrial dysfunction drives inflammation and airway smooth muscle remodeling in patients with chronic obstructive pulmonary disease. $J$ Allergy Clin Immunol 2015; 136: 769-780.

Aravamudan B, Kiel A, Freeman M, et al. Cigarette smoke-induced mitochondrial fragmentation and dysfunction in human airway smooth muscle. Am J Physiol Lung Cell Mol Physiol 2014; 306: L840-L854.

Aravamudan B, Thompson M, Sieck GC, et al. Functional effects of cigarette smoke-induced changes in airway smooth muscle mitochondrial morphology. J Cell Physiol 2017; 232: 1053-1068.

Hara H, Araya J, Ito S, et al. Mitochondrial fragmentation in cigarette smoke-induced bronchial epithelial cell senescence. Am J Physiol Lung Cell Mol Physiol 2013; 305: L737-L746.

liang Y, Wang X, Hu D. Mitochondrial alterations during oxidative stress in chronic obstructive pulmonary disease. Int J Chron Obstruct Pulmon Dis 2017; 12: 1153-1162.

Ahmad T, Sundar IK, Lerner CA, et al. Impaired mitophagy leads to cigarette smoke stress-induced cellular senescence: implications for chronic obstructive pulmonary disease. FASEB J 2015; 29: 2912-2929. 
Mercado N, Colley T, Baker JR, et al. Bicaudal D1 impairs autophagosome maturation in chronic obstructive pulmonary disease. FASEB Bioadv 2019; 1: 688-705.

Cloonan SM, Glass K, Laucho-Contreras ME, et al. Mitochondrial iron chelation ameliorates cigarette smoke-induced bronchitis and emphysema in mice. Nat Med 2016; 22: 163-174.

Wu G, Zhu Q, Zeng J, et al. Extracellular mitochondrial DNA promote NLRP3 inflammasome activation and induce acute lung injury through TLR9 and NF-кB. J Thorac Dis 2019; 11: 4816-4828.

Horng T. Calcium signaling and mitochondrial destabilization in the triggering of the NLRP3 inflammasome. Trends Immunol 2014; 35: 253-261.

Zhou R, Yazdi AS, Menu P, et al. A role for mitochondria in NLRP3 inflammasome activation. Nature 2011; 469: 221-225.

West AP, Khoury-Hanold W, Staron M, et al. Mitochondrial DNA stress primes the antiviral innate immune response. Nature 2015; 520: 553-557.

Szczesny B, Marcatti M, Ahmad A, et al. Mitochondrial DNA damage and subsequent activation of Z-DNA binding protein 1 links oxidative stress to inflammation in epithelial cells. Sci Rep 2018; 8: 914.

Zhang WZ, Rice MC, Hoffman KL, et al. Association of urine mitochondrial DNA with clinical measures of COPD in the SPIROMICS cohort. JCI Insight 2020; 5: e133984.

Taivassalo T, Hussain SN. Contribution of the mitochondria to locomotor muscle dysfunction in patients with COPD. Chest 2016; 149: 1302-1312.

Zong WX, Rabinowitz JD, White E. Mitochondria and cancer. Mol Cell 2016; 61: 667-676.

Akgul EO, Kurt B, Gulcan Kurt Y, et al. MtDNA depletions and deletions may also be important in pathogenesis of lung cancer. Respir Med 2013; 107: 1814.

Wang L, Chen ZJ, Zhang YK, et al. The role of mitochondrial tRNA mutations in lung cancer. Int J Clin Exp Med 2015; 8: 13341-13346.

Liu F, Sanin DE, Wang X. Mitochondrial DNA in lung cancer. Adv Exp Med Biol 2017; 1038: 9-22.

Fetterman JL, Sammy MJ, Ballinger SW. Mitochondrial toxicity of tobacco smoke and air pollution. Toxicology 2017; 391: 18-33.

Adcock IM, Caramori G, Barnes PJ. Chronic obstructive pulmonary disease and lung cancer: new molecular insights. Respiration 2011; 81: 265-284.

Ng Kee Kwong F, Nicholson AG, Harrison CL, et al. Is mitochondrial dysfunction a driving mechanism linking COPD to nonsmall cell lung carcinoma? Eur Respir Rev 2017; 26: 170040.

Caramori G, Adcock IM, Casolari P, et al. Unbalanced oxidant-induced DNA damage and repair in COPD: a link towards lung cancer. Thorax 2011; 66: 521-527.

Hung JJ, Yang MH, Hsu HS, et al. Prognostic significance of hypoxia-inducible factor-1alpha, TWIST1 and Snail expression in resectable non-small cell lung cancer. Thorax 2009; 64: 1082-1089.

Kong H, Wang Y, Zeng X, et al.
Tumour Biol 2015; 36: 7501-7513.

Musher DM, Thorner AR. Community-acquired pneumonia. N Engl J Med 2014; 371: 1619-1628.

Iuliano $\mathrm{AD}$, Roguski $\mathrm{KM}$, Chang $\mathrm{HH}$, et al. Estimates of global seasonal influenza-associated respiratory mortality: a modelling study. Lancet 2018; 391: 1285-1300.

Plataki M, Cho SJ, Harris RM, et al. Mitochondrial dysfunction in aged macrophages and lung during primary Streptococcus pneumoniae infection is improved with pirfenidone. Sci Rep 2019; 9: 971.

Graef KM, Vreede FT, Lau YF, et al. The PB2 subunit of the influenza virus RNA polymerase affects virulence by interacting with the mitochondrial antiviral signaling protein and inhibiting expression of beta interferon. $J$ Virol 2010; 84: 8433-8445.

Carr SM, Carnero E, García-Sastre A, et al. Characterization of a mitochondrial-targeting signal in the PB2 protein of influenza viruses. Virology 2006; 344: 492-508.

Nerlich A, Mieth M, Letsiou E, et al. Pneumolysin induced mitochondrial dysfunction leads to release of mitochondrial DNA. Sci Rep 2018; 8: 182.

Gao Y, Xu W, Dou X, et al. Mitochondrial DNA leakage caused by Streptococcus pneumoniae hydrogen peroxide promotes type I IFN expression in lung cells. Front Microbiol 2019; 10: 630.

Chen BB, Coon TA, Glasser JR, et al. E3 ligase subunit Fbxo15 and PINK1 kinase regulate cardiolipin synthase 1 stability and mitochondrial function in pneumonia. Cell Rep 2014; 7: 476-487.

antiviral therapy. Nat Commun 2017; 8: 69.

Vlahos R, Stambas J, Bozinovski S, et al. Inhibition of Nox2 oxidase activity ameliorates influenza A virus-induced lung inflammation. PLoS Pathog 2011; 7: e1001271. Tom40 channels and impairs innate immunity. Nat Commun 2014; 5: 4713.

Long JC, Fodor E. The PB2 subunit of the influenza A virus RNA polymerase is imported into the mitochondrial matrix. J Virol 2016; 90: 8729-8738.

Wang $\mathrm{R}$, Zhu Y, Lin X, et al. Influenza M2 protein regulates MAVS-mediated signaling pathway through interacting with MAVS and increasing ROS production. Autophagy 2019; 15: 1163-1181.

Wang R, Zhu Y, Ren C, et al. Influenza A virus protein PB1-F2 impairs innate immunity by inducing mitophagy. Autophagy 2020: 93: e01984-18.

8 Sinshaw W, Kebede A, Bitew A, et al. Prevalence of tuberculosis, multidrug resistant tuberculosis and associated risk factors among smear negative presumptive pulmonary tuberculosis patients in Addis Ababa, Ethiopia. BMC infectious diseases 2019; 19: 641.

9 Sia JK, Rengarajan J. Immunology of Mycobacterium tuberculosis infections. Microbiol Spectr 2019; 7: https://doi. org.10.1128/microbiolspec.GPP3-0022-2018.

Koenig SP, Furin J. Update in tuberculosis/pulmonary infections 2015. Am J Respir Crit Care Med 2016; 194: 142-146.

Teale C, Goldman JM, Pearson SB. The association of age with the presentation and outcome of tuberculosis: a five-year survey. Age Ageing 1993; 22: 289-293. 
Liu M, Li W, Xiang X, et al. Mycobacterium tuberculosis effectors interfering host apoptosis signaling. Apoptosis 2015; 20: 883-891.

Pajuelo D, Gonzalez-Juarbe N, Tak U, et al. NAD+ depletion triggers macrophage necroptosis, a cell death pathway exploited by Mycobacterium tuberculosis. Cell Rep 2018; 24: 429-440.

Behar SM, Martin CJ, Booty MG, et al. Apoptosis is an innate defense function of macrophages against Mycobacterium tuberculosis. Mucosal Immunol 2011; 4: 279-287.

Rottinghaus EK, Vesosky B, Turner J. TLR-2 independent recognition of Mycobacterium Tuberculosis by CD11c+ pulmonary cells from old mice. Mech Ageing Dev 2010; 131: 405-414.

Gleeson LE, Sheedy FJ, Palsson-McDermott EM, et al. Cutting edge: Mycobacterium tuberculosis induces aerobic glycolysis in human alveolar macrophages that is required for control of intracellular bacillary replication. $J$ Immunol 2016; 196: 2444-2449.

Cumming BM, Addicott KW, Adamson JH, et al. Mycobacterium tuberculosis induces decelerated bioenergetic metabolism in human macrophages. Elife 2018; 7: e39169.

Herridge MS, Angus DC. Acute lung injury - affecting many lives. N Engl J Med 2005; 353: 1736-1738.

Johnston CJ, Rubenfeld GD, Hudson LD. Effect of age on the development of ARDS in trauma patients. Chest 2003; 124: 653-659.

Thompson BT, Chambers RC, Liu KD. Acute respiratory distress syndrome. N Engl J Med 2017; 377: 562-572.

Schenck EJ, Oromendia C, Torres LK, et al. Rapidly improving ARDS in therapeutic randomized controlled trials. Chest 2019; 155: 474-482.

Puthucheary ZA, Astin R, McPhail MJW, et al. Metabolic phenotype of skeletal muscle in early critical illness. Thorax 2018; 73: 926-935.

Dorward DA, Lucas CD, Doherty MK, et al. Novel role for endogenous mitochondrial formylated peptide-driven formyl peptide receptor 1 signalling in acute respiratory distress syndrome. Thorax 2017; 72: 928-936.

Grazioli S, Dunn-Siegrist I, Pauchard LA, et al. Mitochor
lung injury and ARDS. PLoS One 2019; 14: e0225468.

Nakahira K, Kyung SY, Rogers AJ, et al. Circulating mitochondrial DNA in patients in the ICU as a marker of mortality: derivation and validation. PLoS Med 2013; 10: e1001577; discussion e1001577.

Rosenbaum RM, Wittner M, Lenger M. Mitochondrial and other ultrastructural changes in great alveolar cells of oxygen-adapted and poisoned rats. Lab Invest 1969; 20: 516-528.

Plataki M, Fan L, Sanchez E, et al. Fatty acid synthase downregulation contributes to acute lung injury in murine diet-induced obesity. JCI Insight 2019; 5: e127823.

Lin JY, Jing R, Lin F, et al. High tidal volume induces mitochondria damage and releases mitochondrial DNA to aggravate the ventilator-induced lung injury. Front Immunol 2018; 9: 1477.

Hashizume M, Mouner M, Chouteau JM, et al. Mitochondrial-targeted DNA repair enzyme 8-oxoguanine DNA glycosylase 1 protects against ventilator-induced lung injury in intact mice. Am J Physiol Lung Cell Mol Physiol 2013; 304: L287-L297.

Siempos II, Ma KC, Imamura M, et al. RIPK3 mediates pathogenesis of experimental ventilator-induced lung injury. JCI Insight 2018; 3: e97102.

Mannam P, Shinn AS, Srivastava A, et al. MKK3 regulates mitochondrial biogenesis and mitophagy in sepsis-induced lung injury. Am J Physiol Lung Cell Mol Physiol 2014; 306: L604-L619.

Al-Mehdi AB, Pastukh VM, Swiger BM, et al. Perinuclear mitochondrial clustering creates an oxidant-rich nuclear domain required for hypoxia-induced transcription. Sci Signal 2012; 5: ra47.

Chang AL, Ulrich A, Suliman HB, et al. Redox regulation of mitophagy in the lung during murine Staphylococcus aureus sepsis. Free Radic Biol Med 2015; 78: 179-189.

Athale J, Ulrich A, MacGarvey NC, et al. Nrf2 promotes alveolar mitochondrial biogenesis and resolution of lung injury in Staphylococcus aureus pneumonia in mice. Free Radic Biol Med 2012; 53: 1584-1594.

Wang Q, Wang J, Hu M, et al. Uncoupling protein 2 increases susceptibility to lipopolysaccharide-induced acute lung injury in mice. Mediators Inflamm 2016; 2016: 9154230.

Moon JS, Lee S, Park MA, et al. UCP2-induced fatty acid synthase promotes NLRP3 inflammasome activation during sepsis. J Clin Invest 2015; 125: 665-680.

Jackson MV, Morrison TJ, Doherty DF, et al. Mitochondrial transfer via tunneling nanotubes is an important mechanism by which mesenchymal stem cells enhance macrophage phagocytosis in the in vitro and in vivo models of ARDS. Stem Cells 2016; 34: 2210-2223.

Morrison TJ, Jackson MV, Cunningham EK, et al. Mesenchymal stromal cells modulate macrophages in clinically relevant lung injury models by extracellular vesicle mitochondrial transfer. Am J Respir Crit Care Med 2017; 196: 1275-1286.

Sundaresan NR, Bindu S, Pillai VB, et al. SIRT3 blocks aging associated tissue fibrosis in mice by deacetylating and activating glycogen synthase kinase 33. Mol Cell Biol 2015; 36: 678-692.

0 Bernard K, Logsdon NJ, Ravi S, et al. Metabolic reprogramming is required for myofibroblast contractility and differentiation. J Biol Chem 2015; 290: 25427-25438.

1 Negmadjanov U, Godic Z, Rizvi F, et al. TGF- $\beta 1$ mediated differentiation of fibroblasts is associated with increased mitochondrial content and cellular respiration. PLoS One 2015; 10: e0123046.

2 Selvarajah B, Azuelos I, Platé M, et al. mTORC1 amplifies the ATF4 dependent de novo serineglycine pathway to supply glycine during TGF- $\beta 1$ induced collagen biosynthesis. Sci Signal 2019; 12: eaav3048.

Travis WD, Costabel U, Hansell DM, et al. An official American Thoracic Society/European Respiratory Society statement: update of the international multidisciplinary classification of the idiopathic interstitial pneumonias. Am J Respir Crit Care Med 2013; 188: 733-748.

Malsin ES, Kamp DW. The mitochondria in lung fibrosis: friend or foe? Transl Res 2018; 202: 1-23.

Alvarez D, Cardenes N, Sellares J, et al. IPF lung fibroblasts have a senescent phenotype. Am J Physiol Lung Cell Mol Physiol 2017; 313: L1164-L1173.

Xu Y, Mizuno T, Sridharan A, et al. Single-cell RNA sequencing identifies diverse roles of epithelial cells in idiopathic pulmonary fibrosis. JCI Insight 2016; 1: e90558. 
Patel AS, Song JW, Chu SG, et al. Epithelial cell mitochondrial dysfunction and PINK1 are induced by transforming growth factor-beta1 in pulmonary fibrosis. PLoS One 2015; 10: e0121246.

Ryu C, Sun H, Gulati M, et al. Extracellular mitochondrial DNA is generated by fibroblasts and predicts death in idiopathic pulmonary fibrosis. Am J Respir Crit Care Med 2017; 196: 1571-1581.

Cho HY, Reddy SP, Yamamoto M, et al. The transcription factor NRF2 protects against pulmonary fibrosis. FASEB J 2004; 18: 1258-1260.

Kim SJ, Cheresh P, Jablonski RP, et al. Mitochondrial catalase overexpressed transgenic mice are protected against lung fibrosis in part via preventing alveolar epithelial cell mitochondrial DNA damage. Free Radic Biol Med 2016; 101: 482-490.

Ganzleben I, He GW, Gunther C, et al. PGAM5 is a key driver of mitochondrial dysfunction in experimental lung fibrosis. Cell Mol Life Sci 2019; 76: 4783-4794.

Lombardi AA, Gibb AA, Arif E, et al. Mitochondrial calcium exchange links metabolism with the epigenome to control cellular differentiation. Nat Commun 2019; 10: 4509.

Caporarello N, Meridew JA, Jones DL, et al. PGC1 $\alpha$ repression in IPF fibroblasts drives a pathologic metabolic, secretory and fibrogenic state. Thorax 2019; 74: 749-760.

O'Leary EM, Tian Y, Nigdelioglu R, et al. TGF- $\beta$ promotes metabolic reprogramming in lung fibroblasts via mTORC1-dependent ATF4 activation. Am J Respir Cell Mol Biol 2020.

Larson-Casey JL, Deshane JS, Ryan AJ, et al. Macrophage Akt1 kinase-mediated mitophagy modulates apoptosis resistance and pulmonary fibrosis. Immunity 2016; 44: 582-596.

Tsitoura E, Vasarmidi E, Bibaki E, et al. Accumulation of damaged mitochondria in alveolar macrophages with reduced OXPHOS related gene expression in IPF. Respir Res 2019; 20: 264.

Ding BS, Nolan DJ, Guo P, et al. Endothelial-derived angiocrine signals induce and sustain regenerative lung alveolarization. Cell 2011; 147: 539-553.

Vila Ellis L, Cain MP, Hutchison V, et al. Epithelial Vegfa specifies a distinct endothelial population in the mouse lung. Dev Cell 2020; 52: 617-630 e616.

Development 2016; 143: 54-65.

Coffman KE, Boeker MG, Carlson AR, et al. Age dependent effects of thoracic and capillary blood volume distribution on pulmonary artery pressure and lung diffusing capacity. Physiol Rep 2018; 6: e13834.

Xin MG, Zhang J, Block ER, et al. Senescence-enhanced oxidative stress is associated with deficiency of mitochondrial cytochrome c oxidase in vascular endothelial cells. Mech Ageing Dev 2003; 124: 911-919.

Stone OA, El-Brolosy M, Wilhelm K, et al. Loss of pyruvate kinase M2 limits growth and triggers innate immune signaling in endothelial cells. Nat Commun 2018; 9: 4077.

De Bock K, Georgiadou M, Schoors S, et al. Role of PFKFB3-driven glycolysis in vessel sprouting. Cell 2013; 154: 651-663.

Cruys B, Wong BW, Kuchnio A, et al. Glycolytic regulation of cell rearrangement in angiogenesis. Nat Commun 2016; 7: 12240 .

Quintero M, Colombo SL, Godfrey A, et al. Mitochondria as signaling organelles in the vascular endothelium. Proc Natl Acad Sci USA 2006; 103: 5379-5384.

Diebold I, Hennigs JK, Miyagawa K, et al. BMPR2 preserves mitochondrial function and DNA during reoxygenation to promote endothelial cell survival and reverse pulmonary hypertension. Cell Metab 2015; 21: 596-608.

Montani D, Gunther S, Dorfmuller P, et al. Pulmonary arterial hypertension. Orphanet J Rare Dis 2013; 8: 97.

$\mathrm{Xu} \mathrm{W}$, Koeck T, Lara AR, et al. Alterations of cellular bioenergetics in pulmonary artery endothelial cells. Proc Natl Acad Sci USA 2007; 104: 1342-1347.

Ryan JJ, Marsboom G, Fang YH, et al. PGC1alpha-mediated mitofusin-2 deficiency in female rats and humans with pulmonary arterial hypertension. Am J Respir Crit Care Med 2013; 187: 865-878.

Ahting U, Mayr JA, Vanlander AV, et al. Clinical, biochemical, and genetic spectrum of seven patients with NFU1 deficiency. Front Genet 2015; 6: 123. muscle cells via the AMPK-Akt pathway. Nat Commun 2018; 9: 3850

Papandreou I, Cairns RA, Fontana L, et al. HIF-1 mediates adaptation to hypoxia by actively downregulating mitochondrial oxygen consumption. Cell Metab 2006; 3: 187-197.

Rafikova O, Srivastava A, Desai AA, et al. Recurrent inhibition of mitochondrial complex III induces chronic pulmonary vasoconstriction and glycolytic switch in the rat lung. Respir Res 2018; 19: 69.

Rafikov R, Sun X, Rafikova O, et al. Complex I dysfunction underlies the glycolytic switch in pulmonary hypertensive smooth muscle cells. Redox Biol 2015; 6: 278-286.

Enache I, Charles AL, Bouitbir J, et al. Skeletal muscle mitochondrial dysfunction precedes right ventricular impairment in experimental pulmonary hypertension. Mol Cell Biochem 2013; 373: 161-170.

Guzy RD, Hoyos B, Robin E, et al. Mitochondrial complex III is required for hypoxia-induced ROS production and cellular oxygen sensing. Cell Metab 2005; 1: 401-408.

Dunham-Snary KJ, Hong ZG, Xiong PY, et al. A mitochondrial redox oxygen sensor in the pulmonary vasculature and ductus arteriosus. Pflugers Arch 2016; 468: 43-58.

van der Feen DE, Berger RMF, Bartelds B. Converging paths of pulmonary arterial hypertension and cellular senescence. Am J Respir Cell Mol Biol 2019; 61: 11-20.

Guignabert C, Phan C, Seferian A, et al. Dasatinib induces lung vascular toxicity and predisposes to pulmonary hypertension. J Clin Invest 2016; 126: 3207-3218.

Moiseeva O, Deschenes-Simard X, St-Germain E, et al. Metformin inhibits the senescence associated secretory phenotype by interfering with IKK/NF-кB activation. Aging Cell 2013; 12: 489-498.

Agard C, Rolli-Derkinderen M, Dumas-de-La-Roque E, et al. Protective role of the antidiabetic drug metformin against chronic experimental pulmonary hypertension. Br J Pharmacol 2009; 158: 1285-1294.

Houssaini A, Abid S, Mouraret N, et al. Rapamycin reverses pulmonary artery smooth muscle cell proliferation in pulmonary hypertension. Am J Respir Cell Mol Biol 2013; 48: 568-577. 
194 Islam MN, Das SR, Emin MT, et al. Mitochondrial transfer from bone-marrow-derived stromal cells to pulmonary alveoli protects against acute lung injury. Nat Med 2012; 18: 759-765.

195 To EE, Erlich JR, Liong F, et al. Mitochondrial reactive oxygen species contribute to pathological inflammation during influenza A virus infection in mice. Antioxid Redox Signal 2020; 32: 929-942.

$196 \mathrm{Hu}$ M, Schulze KE, Ghildyal R, et al. Respiratory syncytial virus co-opts host mitochondrial function to favour infectious virus production. Elife 2019; 8: e42448.

197 Zhou Z, Song R, Fattman CL, et al. Carbon monoxide suppresses bleomycin-induced lung fibrosis. Am J Pathol 2005; 166: $27-37$. 